\section{Enfermedad de Castleman con manifestación inusual en el seno y parénquima renales. Reporte de un}

\section{caso}

Muñoz-Lumbreras RG, Morales-Ordaz O, Gil-García F, Lujano-Pedraza H, Valdéz-Colín J, Michel-Ramírez JM y colaboradores.

\section{Resumen}

ANTECEDENTES: La enfermedad de Castleman es un padecimiento linfoproliferativo poco frecuente y en algunos casos se relaciona con linfoma maligno. Suele afectar a pacientes jóvenes y su fisiopatología se asocia con elevada concentración de IL-6, incluso con el virus de inmunodeficiencia humana y el herpes virus humano 8.

CASO CLÍNICO: Paciente masculino de 35 años de edad, que inició con hematuria macroscópica intermitente y dolor tipo cólico en la región lumbar derecha. El ultrasonido mostró al riñón derecho de aspecto irregular, con imagen ovoidea en la región parahiliar, que comprimía el seno renal. La tomografía abdominopélvica, simple y contrastada, evidenció una lesión de aspecto sólido en la pelvis renal derecha, con realce a la administración del medio de contraste. El tratamiento consistió en nefroureterectomía con rodete vesical, que se llevó a cabo sin complicaciones. Con el estudio histopatológico se estableció el diagnóstico de enfermedad de Castleman, variedad mixta, que afectaba el seno e infiltraba el parénquima renal.

CONCLUSIONES: La importancia de este caso radica en la manifestación inusual de la enfermedad de Castleman, expresada en el seno y parénquima renales, simulando un cuadro con neoplasia de origen renal o urotelial.

PALABRAS CLAVE: Enfermedad de Castleman; nefroureterectomía; rodete vesical; parénquima renal; neoplasia urotelial.

Rev Mex Urol. 2018 Jan-Feb;78(1):62-66.

\section{Castleman's disease with unusual involvement of the renal sinus and renal parynchema: A case report}

Muñoz-Lumbreras RG, Morales-Ordaz O, Gil-García F, Lujano-Pedraza H, Valdéz-Colín J, Michel-Ramírez JM y colaboradores.

\section{Abstract}

BACKGROUND: Castleman's disease is a rare lymphoproliferative pathology, sometimes related to malignant lymphoma. The disease
División de Urología, Centro Médico Lic. Adolfo López Mateos, Instituto de Salud del Estado de México, Toluca.

Recibido: octubre 2017

Aceptado: enero 2018

Correspondencia

Eddy Gabriel Muñoz Lumbreras

gabriel.lumbreras@gmail.com

Este artículo debe citarse como

Muñoz-Lumbreras RG, Morales-Ordaz O, GilGarcía F, Lujano-Pedraza H, Valdéz-Colín J, MichelRamírez JM y col. Enfermedad de Castleman con manifestación inusual en el seno y parénquima renal. Reporte de un caso. Rev Mex Urol. 2018 ene-feb;78(1):62-66. DOI: https://doi.org/10.24245/revmexurol.v78i1.1457 
usually affects young patients and its pathophysiology is associated with elevated IL-6 levels, as well as human immunodeficiency virus and human herpesvirus-8.

CLINICAL CASE: A 35-year-old man had disease onset with gross intermittent hematuria and colicky pain in the right lumbar region. Ultrasound imaging detected an irregular-appearing right kidney with an ovoid image at the parahilar level, compressing the renal sinus. Contrast and non-contrast-enhanced abdominopelvic tomography identified a solid lesion in the right renal pelvis with contrast enhancement. Nephroureterectomy with bladder cuff excision was performed with no complications. The histopathologic report described the diagnosis of mixed Castleman's disease affecting the renal sinus and infiltrating the renal parenchyma.

CONCLUSIONS: The importance of this case was its unusual disease presentation in the renal sinus and renal parenchyma, simulating a urothelial tumor.

KEYWORDS: Castleman's disease; Nephroureterectomy; Bladder cuff; Renal parenchyma; Urothelial tumor.

\section{ANTECEDENTES}

La enfermedad de Castleman es un padecimiento linfoproliferativo poco frecuente y en algunos casos se relaciona con linfoma maligno. ${ }^{1}$ En 1954, Benjamin Castleman describió la alteración en un paciente con nódulo hiperplásico mediastinal. Esta enfermedad también se conoce como; hiperplasia gigante de ganglios linfáticos, hamartoma de ganglios linfáticos, linforreticuloma folicular, linfoma gigante benigno o hamartoma gigante angiomatoso. ${ }^{2,3}$

\section{CASO CLÍNICO}

Paciente masculino de 35 años de edad, sin antecedentes médicos de importancia para el padecimiento actual, con antecedente de tabaquismo crónico (2 a 3 cigarros por día desde los 15 años de edad) y alcoholismo social.

Cinco meses antes de acudir al servicio médico inició, de forma intermitente, con hematuria macroscópica en forma de coágulos cilíndricos; posteriormente manifestó dolor súbito en la región lumbar del lado derecho, de moderada intensidad, con exacerbación de los episodios de hematuria. Negó pérdida de peso, malestar general o fiebre.

El ultrasonido mostró al riñón derecho con pérdida de la morfología externa, con contornos irregulares y mala diferenciación corticomedular; en la región parahiliar se observó una imagen ovoidea, bien delimitada, heterogénea, que desplazaba y comprimía el seno renal, características compatibles con una lesión de aspecto sólido (Figura 1).

El protocolo se complementó con tomografía abdominopélvica, simple y contrastada, que evidenció una lesión de aspecto sólido en la pelvis renal derecha, de $10.8 \times 7.6 \times 6.7$, con calcificaciones gruesas en su interior; lesión con anatomía renal distorsionada, densidades en fase simple de 10 y $57 \mathrm{UH}$, con realce al medio de contraste de 24 a $87 \mathrm{UH}$. 


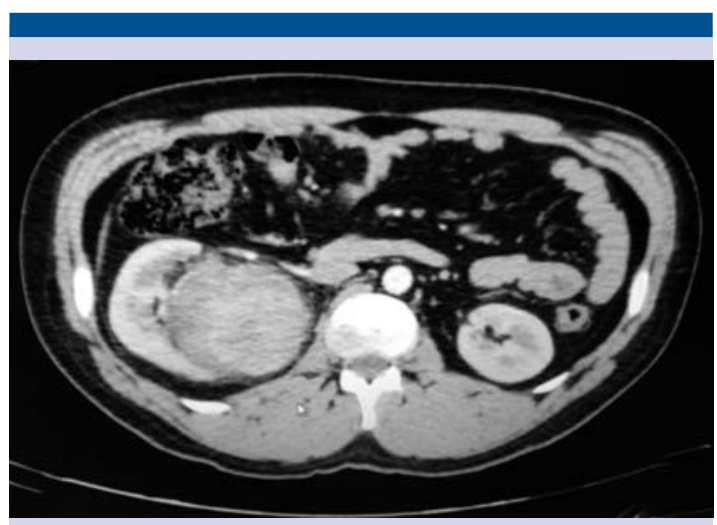

Figura 1. Tomografía abdominopélvica contrastada que muestra una lesión sólida en el seno renal, al parecer dependiente de la pelvis renal. Se observa la lesión con la administración del medio de contraste; en la región posterior parece perder la interfase, entre la lesión y el parénquima renal.

Después de la evaluación del paciente se decidió efectuar nefroureterectomía derecha con rodete vesical, sin complicaciones transquirúrgicas. El estudio histopatológico de la pieza quirúrgica reportó, al corte del seno renal, dos nódulos de $8 \times 4 \mathrm{~cm}$, ambos encapsulados, de color marrón oscuro y áreas claras del mismo color. Las lesiones desplazaban el parénquima renal, además de infiltrarlo y comprimir el sistema pielo-calicial. Con el estudio histopatológico se estableció el diagnóstico de enfermedad de Castleman, variedad mixta en los ganglios linfáticos del seno renal (Figura 2).

\section{DISCUSIÓN}

La enfermedad de Castleman es un padecimiento linfoproliferativo, atípico y en algunos casos asociado con linfoma maligno. Afecta predominantemente a pacientes adultos jóvenes, de entre 20 y 40 años de edad. Desde el punto de vista clínico, aparece en el tórax, aunque se han descrito formas extratorácicas, que representan casos excepcionales. La enfermedad de Castleman en el seno o parénquima renal es extremadamente rara. ${ }^{4-6}$
Hasta el momento se desconoce la patogenia de la enfermedad; sin embargo, algunas teorías sugieren su asociación con el virus de inmunodeficiencia humana y el virus herpes humano 8 , debido a la producción anormal de interleucina 6, que resulta en linfoproliferación y diferenciación de células plasmáticas. ${ }^{7}$

En la patogénesis de la enfermedad de Castleman también intervienen algunos mediadores inflamatorios. En este caso, la interleucina-6 (IL-6) estimula de forma directa la proliferación de células B y se expresa en los tejidos afectados por la enfermedad de Castleman. Algunos estudios demuestran que el aumento de la producción de IL-6 provoca síntomas similares a la enfermedad de Castleman.

La IL-6 del virus herpes humano 8 también puede generar la enfermedad de Castleman, pues favorece la inducción del factor de crecimiento del endotelio vascular y la angiogénesis, además de estimular la proliferación de células B. Otros mediadores implicados en la enfermedad de Castleman son el factor de crecimiento epidérmico y el interferón alfa. ${ }^{8,9}$

La enfermedad de Castleman se clasifica de acuerdo con los hallazgos histopatológicos: ${ }^{1}$

a. Variedad hialino-vascular: no genera síntomas y las lesiones son localizadas.

b. Variedad de células plasmáticas: suele ser multicéntrico y es la variante menos común, pero relacionada con infección por VIH.

c. Variedad mixta.

El tipo hialino-vascular se caracteriza por pequeños folículos hialinos vasculares y proliferación capilar interfolicular. Aparece en $90 \%$ de los pacientes y generalmente cursan asintomáticos. 


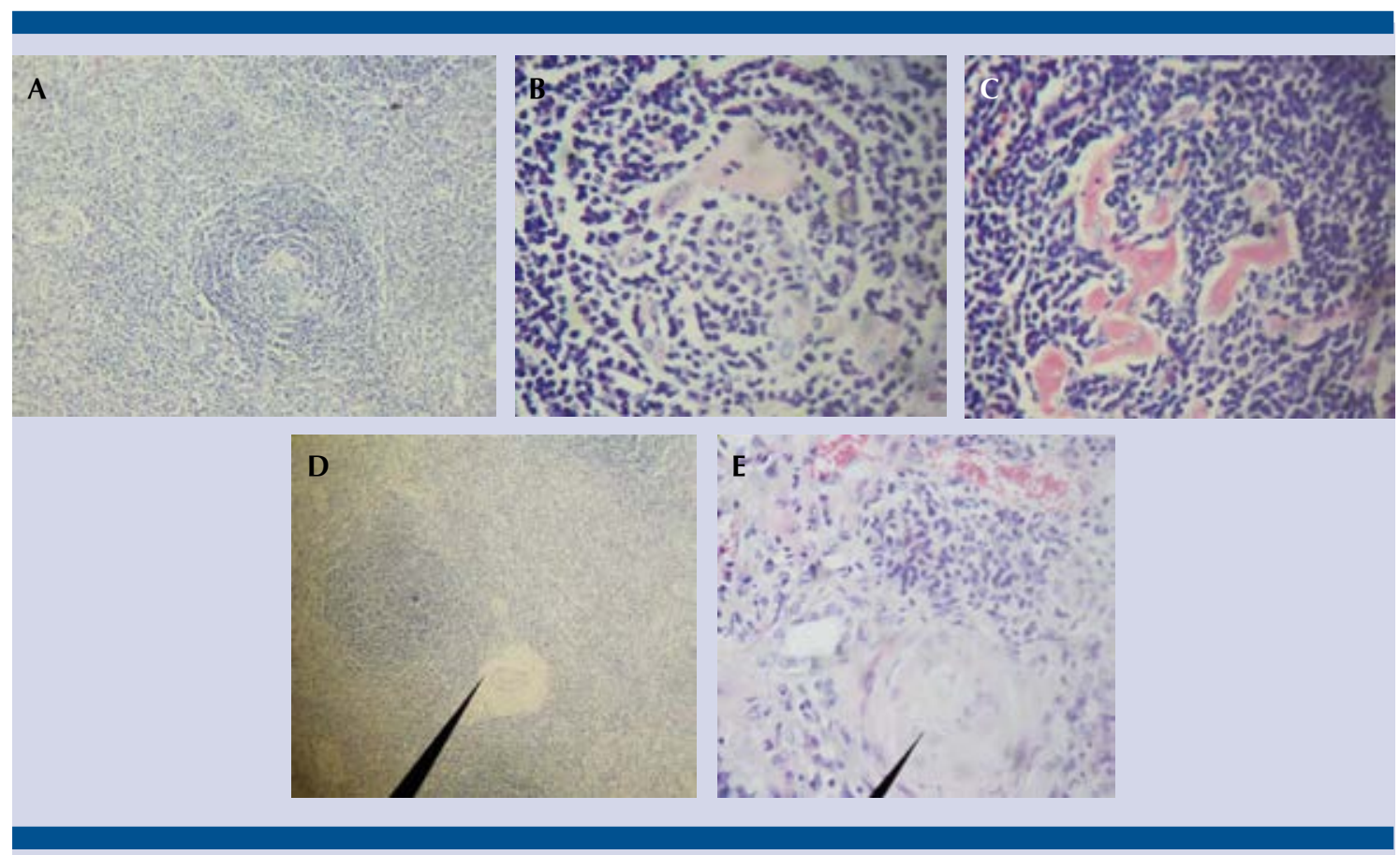

Figura 2. (A) Tinción con hematoxilina-eosina (10X). Se observan folículos linfoides con disposición concéntrica de los linfocitos en la periferia de los folículos. (B) Microscopia (40X). Acercamiento al centro germinal, en el que se observa hialinización. (C) Cambio hialino-vascular en el centro de los folículos linfoides. (D) La punta de la flecha muestra la zona de hialinización de un vaso. (E) La punta de la flecha evidencia glomérulos con esclerosis global.

El tipo de células plasmáticas es el menos frecuente; se distingue por largos folículos con inclusiones de células plasmáticas, con mucho menos vascularidad. Esta variante genera síntomas como: fiebre, malestar general, disnea, pérdida de peso, anemia, trombocitosis e hipergammaglobulinemia. ${ }^{1,2}$ Además, suele afectar a más de un órgano y provocar síntomas generales (astenia, fiebre, mal estado general, hepatoesplenomegalia), incluso hipergammaglobulinemia y aumento de la velocidad de sedimentación globular. Frecuentemente se asocia con inmunodeficiencias, infecciones, sarcoma de Kaposi (13\%), linfoma (18\%), microangiopatías, carcinomas (colon, riñón y tiroides), entre otras afecciones. ${ }^{1,2,9}$
La tomografía puede reportar adenopatías difusas y homogéneas en diferentes compartimientos mediastínicos, asociadas con esplenomegalia o hepatomegalia.

La enfermedad de Castleman hialino-vascular, comparada con la variante plasmo-celular, es una enfermedad asintomática, cuyo diagnóstico se establece de manera fortuita en las radiografías u otros estudios de imagen. En los pacientes que manifiestan síntomas suele deberse al efecto compresivo de la masa.

El diagnóstico preoperatorio es difícil de establecer, debido a las características clínicas y radiológicas inespecíficas. La punción por aspiración con aguja fina no representa una 
técnica efectiva para establecer el diagnóstico. ${ }^{10,11}$

El parénquima y seno renales son sitios extremadamente raros de localización de la enfermedad de Castleman. ${ }^{12,13}$

El mecanismo por el que se origina en el riñón (que normalmente no contiene tejido linfoide) puede ser similar al que ocurre en pacientes con linfoma renal, es decir, el tumor puede aparecer a través del tejido linfático (en la cápsula renal o en la grasa perirrenal) y de esta forma invadir el parénquima o el seno renal. Incluso puede originarse en los nódulos de áreas de inflamación crónica. ${ }^{14-17}$

Nishie y sus colaboradores reportaron tres casos de enfermedad de Castleman en el seno renal: dos de variedad de células plasmáticas y uno de variedad mixta. ${ }^{18}$

La importancia de este caso radica en la manifestación inusual de la enfermedad de Castleman, expresada en el seno y parénquima renales, simulando un cuadro con neoplasia de origen renal o urotelial.

\section{Financiamiento}

Los autores declaran no haber recibido patrocinio para realizar este estudio.

\section{Conflicto de interés}

Los autores declaran no tener conflicto de interés.

\section{REFERENCIAS}

1. Wang JH. Castleman's disease. Urol Sci 2015;1-3.

2. Paratore A, Herts B. Castleman Disease. J Urol. 2015;194: 529-530.
3. Jongsma TEF, Verburg RJ, Geelhoed-Duijvestigin LM. Castleman's disease: A rare lymphoproliferative disorder. Eur J Int Med. 2007;18:87-89.

4. Luo J, Li S, Hui H, Cao J, Bi YI, Feng R, et al. Clinical spectrum of intrathoracic Castleman disease: a retrospective analysis of 48 cases in a single Chinese hospital. BMC Pulmonary Medicine. 2015;15:34

5. Dispenzieri A, Armitage J, Loe M, Geyer S, Allred J, Camorlano J, et al. The clinical spectrum of Castleman's disease. Am J Hematol. 2012;87(11):997-1002.

6. Bonekamp D, Hruban R, Fishman E. The great mimickers: Castleman disease. Semin Ultrasound CT MRI. 2014;35:263-271.

7. Talat N, Schulte KM. Castleman's disease: Systematic Analysis of 416 patients from the literature. Oncologist. 2011;16:1316-1324.

8. El-Osta H, Kurzrock R. Castleman's disease: from de basic mechanisms to molecular therapeutics. Oncologist. 2011;16:497-511.

9. Hill $A J$, Tirumani $S H$, Rosenthal $M H$, Shinagare $A B$, et al Multimodality imaging and clinical features in Castleman disease: single institute experience in 30 patients. $\mathrm{Br} \mathrm{J}$ Radiol. 2015; 88:20140670.

10. Ooi CC, Cheah FK, Wong SK. Castleman's disease of the kidney: Sonographic findings. J Clin Ultrasound. 2015;43(7):438-442.

11. Madan R, Chen JH, Trotman-Dickenson B, Jacobson F, Hunsaker A. The spectrum of Castleman's disease: mimic's, radiologic pathologic correlation and role of imaging in patient management. Eur J Radiol. 2012;81:123-131.

12. Jang SM, Han H, Jang KS, Jun YJ, Lee TY, Paik SS. Castleman's disease of the renal sinus presenting as a urothelial malignancy: A brief case report. Korean J Pathol. 2012:46:503-506.

13. Karoui KE, Vuiblet V, Dion D, Izzedine H, Guitard J, Frimat L, et. al. Renal involvement in Castleman disease. Nephrol Dial Transplant. 2011;26:599-609.

14. Suneja S, Chidambaram M, Herzenberg A, Bargman J. Kidney involvement in multicentric Castleman Disease. Am J Kidney Dis. 2009;53(3):550-554.

15. Tolofari SK, Chow WM, Hussain B. Castleman's disease: An interesting cause of hematuria. Urol Case Rep 2015:3:24-26

16. Mah N, Peretsman S, Teigland C, Banks P. Castleman disease of the Hyaline-Vascular type confined to the kidney. Am J Clin Pathol. 2007;127:465-468.

17. Kwon JH, Min SK, Shin MK, Lee YS, Lee YG, Ko YH. Hyaline vascular Castleman disease involving renal parenchyma and a lymph node: a case report. Korean J Pathol. 2012:46:79-82.

18. Nishie A, Yoshuimitsu K, Irie H, Aibe H, Tajima T, Shinosaky K, et al. Radiologic features of Castleman's disease occupying the renal sinus. Am J Roentgenol. 2003;181:1037-1040. 